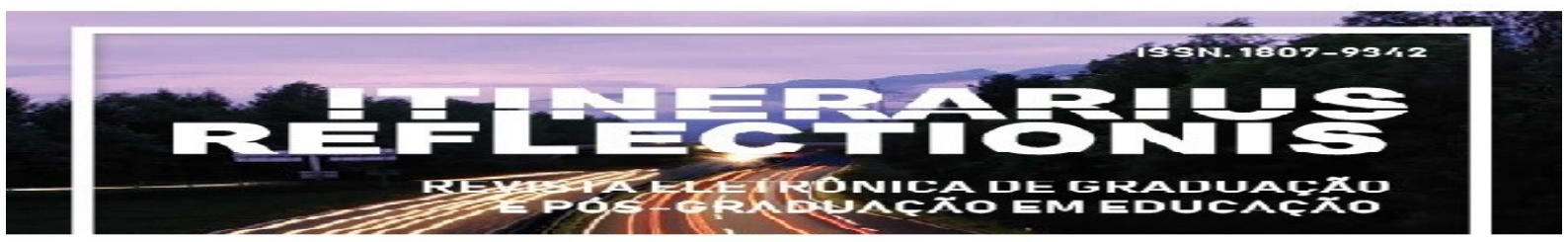

Volume, 15, número 1, ano 2019.

\title{
DIFICULDADES PEDAGÓGICAS NO ESTÁGIO SUPERVISIONADO E A NECESSIDADE DA FORMAÇÃO PARA O OLHAR INVESTIGATIVO
}

\section{PEDAGOGICAL DIFFICULTIES IN THE SUPERVISED STAGE AND THE NEED FOR TRAINING FOR THE INVESTIGATIVE LOOK}

\author{
Patrícia do Nascimento ${ }^{1}$ \\ Sandro Rogério Vargas Ustra ${ }^{2}$
}

\begin{abstract}
Resumo. Esse trabalho constitui-se no recorte de uma pesquisa de mestrado mais ampla que teve como objetivo investigar as principais dificuldades pedagógicas encontradas no processo de formação de professores de Ciências e Biologia, durante as disciplinas de estágio supervisionado. Os sujeitos são estagiários e egressos do Curso de Ciências Biológicas/Noturno da Universidade Federal de Uberlândia. A coleta de dados ocorreu por meio de questionários abertos que envolveram 16 estagiários e 17 egressos. Por meio de uma abordagem qualitativa e através da análise de conteúdo das respostas, construímos categorias relacionadas às principais dificuldades formativas de acordo com a percepção dos próprios participantes. A análise dessas categorias indica que não basta aos licenciandos entrarem em contato com o ambiente do qual fizeram parte por muitos anos em sua formação escolar básica, sem a necessária fundamentação teórica para constituir um olhar efetivamente perscrutador e uma capacidade de enfrentamento das dificuldades encontradas. Também é necessário (re)considerar a importância do estágio, especialmente na articulação da formação inicial para a continuada, visto que é nesse espaço/tempo que o licenciando começa a formar um ideal sobre o que é efetivamente ser professor e inicia sua entrada no âmbito escolar, numa perspectiva profissional.
\end{abstract}

Palavras-chave: Estágio supervisionado. Formação de professores. Necessidades formativas.

\begin{abstract}
This work constitutes a cut of a broader masters research that aimed to investigate the main pedagogical difficulties encountered in the process of training teachers of Science and Biology during supervised internship. The subjects are trainees and graduates of the Biological Sciences/Nocturnal Course of the Federal University of Uberlândia. Data were collected through open questionnaires involving 16 trainees and 17 graduates. Through a qualitative approach and through content analysis of the answers, we constructed categories related to the main formative difficulties according to the perception of the participants themselves. The analysis of these categories indicates that it is not enough for the undergraduates to come into contact with the environment of which they were part for many years of their formation, without the necessary theoretical foundation to constitute an effectively searching look and a capacity to face the identified difficulties. It is also necessary to reconsider the importance of the internship, especially in the articulation of initial and continuing training, since it is
\end{abstract}

\footnotetext{
${ }^{1}$ Universidade Federal de Uberlândia

${ }^{2}$ Universidade Federal de Uberlândia
} 
in this space/time that the undergraduate begins to form an ideal about what is effectively to be a teacher and initiates its entry into the scope School, from a professional perspective.

Keywords: Supervised training. Teacher training. Formative needs. 


\section{INTRODUÇÃO}

A educação é responsável pelo desenvolvimento do senso crítico e da autonomia dos indivíduos, contribuindo assim para o progresso social e econômico de um país. Por isso a formação de novos professores possui extrema importância e se torna uma prioridade; o professor atua diretamente no contexto formativo básico, capaz de promover novas formas de saber e de praticar esse saber, visando um futuro consciente, de transformações e voltado para o bem comum em sociedade.

Vivemos em uma época de muitas transformações, mudanças científicas, tecnológicas, e também de muitas incertezas, onde a valorização da produtividade cresce a cada dia e se esconde nos múltiplos segmentos da vida humana. A competitividade é o maior dos desafios, gerando atitudes individualistas que conflitam com a vida em comunidade.

Neste emaranhado de aplicações do conhecimento, o professor surge como um profissional importante na vida e no desenvolvimento de crianças, jovens e mesmo adultos de todas as idades. Na atualidade os recursos a serem utilizados são vastos para a implementação de novas práticas metodológicas e didáticas. Porém, para muitos professores, persiste uma grande dificuldade em planejar criteriosamente suas ações pedagógicas.

Este profissional segue na sua epistemologia da prática, construindo e reconstruindo novos saberes e reconfigurando sua profissionalidade. A ação pedagógica se refere a uma ação reflexiva. Ao realizar suas reflexões quanto ao planejamento e desenvolvimento de suas aulas o professor se apropria de diversos conhecimentos provenientes de variados recursos e padrões sociais dos espaços escolares (CICILLINI, 2002).

Torna-se importante ao professor ter consciência dos desafios de sua profissão. Necessita saber cada vez mais não apenas seus conteúdos a serem ministrados, mas também conhecimentos mais amplos, interligados às experiências dos saberes socialmente constituídos, das mudanças que vão acontecendo, das formas de enfrentar os obstáculos como uma instância de aprendizado, inclusive como um alicerce para seu desenvolvimento profissional.

Entretanto, uma das principais causas para o abandono da profissão docente é a falta de apoio e incentivo durante o início da carreira, onde várias barreias são impostas nas instituições de ensino (pouco) acolhedoras dos recém-formados. Contrapondo-se a isso, entende-se que: 
O desenvolvimento profissional, por sua vez, se dá sob um processo dialético e dialógico que impõe uma relação reflexiva contínua do profissional com suas ações pedagógicas cotidianas, suas ações políticas diante de sua categoria, sua troca de informações e experiências com colegas de trabalho e sua produção de conhecimento (CICILLINI, 2010, p. 30).

Ensinar contempla variados métodos e estratégias que possibilitam a quem ensina "transmitir" (numa concepção não indutivista) o saber de forma criteriosa, tanto prática quanto teoricamente; o professor iniciante ao experimentar esses diversos recursos se vislumbra em uma gama de sensações diversas, mobilizando conhecimentos e saberes constituídos durante sua formação e a partir daí começa a traçar seu estilo de trabalho.

Assim o estágio supervisionado é o período de desenvolvimento pré-profissional, previsto na Lei de Diretrizes e Bases da Educação Nacional, onde se possibilita a integração teórica e prática, beneficiando ao estudante com um instrumento prático essencial para seu futuro exercício profissional.

Para isso é imprescindível o desenvolvimento do estágio de forma planejada e criteriosa, porque só assim o futuro professor terá a clareza do que ele enfrentará a cada dia, com condições de compreender e enfrentar os desafios.

[...] As experiências docentes vivenciadas no estágio supervisionado têm papel importante na formação inicial, pois são os estágios, na maioria das vezes, que iniciam o futuro professor no exercício da atividade docente, por isso, as formas de organização e de vivências do estágio são fundamentais para o desenvolvimento de teorias sobre o ensinar/aprender e sobre a profissão docente (MACIEL, 2012, p. 3).

Desta forma, compreender as dificuldades encontradas pelos discentes em formação implica em antever situações problemáticas que os mesmos encontrarão no seu início de percurso profissional e promover um exercício reflexivo com vistas à sua superação. Nesse sentido, é necessário identificar os motivos dessas dificuldades encontradas no desenvolvimento do estágio. Essas dificuldades estão associadas à falta de recursos, às metodologias utilizadas, à desmotivação do aluno quanto à disciplina, e a vários outros pontos que em conjunto requerem sua compreensão.

Foi neste contexto que se originou nosso questionamento sobre quais as principais dificuldades encontradas através da percepção dos licenciandos no decorrer das disciplinas de Estágio Supervisionado do curso de Ciências Biológicas. 
Assim, este estudo teve como objetivo geral investigar as dificuldades encontradas pelos licenciandos durante as intervenções realizadas nas escolas por meio das disciplinas de Estágio Supervisionado.

\section{REVISÃO BIBLIOGRÁFICA}

Os primeiros anos de exercício da profissão para muitos professores são cheios de insegurança e intensos de novidades, onde muitos se sentem perdidos e com dificuldades para conduzir suas atividades pedagógicas, gerando apreensão e desmotivação profissional. Esse primeiro impacto expressa variados sentimentos, onde o professor iniciante deixa de ser denominado aluno e passa a ser chamado professor.

De acordo com Pequiá e Rosa (2010, p. 157), “o impacto de transição da vida acadêmica para a atividade profissional pode ser diminuído através de experiências de trabalho sistematizado, crítico e participante".

Dentro dos cursos de licenciatura o estágio obrigatório configura-se como um caminho para diminuir tais impactos, e procura promover processos para que os licenciandos reflitam sobre o que é ser professor, e como tornar-se professor.

Confrontar o conjunto de circunstâncias estabelecidas pelo estágio supervisionado (obrigatório) pode ser o início de uma fase bastante crítica, ponto crucial da formação inicial e porta de entrada da atuação profissional (intimamente ligada à formação continuada).

As bases dos saberes profissionais são construídas nos primeiros anos de carreira, quando ocorre o confronto com um novo contexto de atuação:

\footnotetext{
Ora, este processo está ligado também à socialização profissional do professor e ao que muitos autores chamaram de "choque com a realidade", "choque de transição" ou ainda "choque cultural", noções que remetem ao confronto inicial com a dura e complexa realidade do exercício da profissão, à desilusão e ao desencanto dos primeiros tempos de profissão e, de maneira geral, à transição da vida de estudante para a vida mais exigente de trabalho (TARDIF, 2007, p. 226).
}

Para que esse processo se torne menos traumático e desmotivador, cabe ao orientador instruir e interagir com os licenciandos, favorecendo um espaço livre para busca de resolver conflitos e problemas que irão surgir. Nesse processo se busca promover a auto realização do próprio sujeito:

É função do educador encaminhar o educando para a descoberta e a prática dos valores por intermédio dos quais a educação ganha sentido e o próprio educando se 
auto realiza o que se efetua por meio do processo ensino-aprendizagem (VALSECCHI e NOGUEIRA, 2002, p. 137).

É com o estágio que o licenciando se insere na profissão, convivendo com situações concretas, muitas vezes contrárias com a realidade idealizada durante sua formação. Esse momento formativo enseja uma postura crítica e reflexiva, fundamental para o futuro professor (ALMEIDA, 2013).

Já no exercício da docência, o período inicial da carreira é um momento bastante crítico, pois os professores visam encontrar seus próprios modos de trabalhar, buscando experienciar situações semelhantes àquelas que passaram enquanto estudantes na graduação e em períodos anteriores (TARDIF e RAYMOND, 2000).

Muitas vezes a formação inicial deixa a desejar no confronto com a realidade e na tentativa de superar os obstáculos que são inevitáveis dentro da profissão docente. Apesar de suas especificidades, o ponto comum é que: "O choque de realidade é algo presente nos professores em início de carreira, embora cada um o vivencie de uma maneira" (AZEVEDO e WILTEMBURG, 2013, p. 13).

Por outro lado, é preciso que se reconheça também que a formação inicial nunca será suficiente para dar conta de todas as dificuldades:

Ao chegar à escola o professor principiante é confrontado com uma realidade desconhecida, deparando-se com múltiplas dificuldades pedagógicas e relacionais, para as quais não foi preparado, nem detém experiência suficiente que lhe traga um conhecimento empírico para enfrentar esse choque com a realidade (ROCHA, 2013, p. 42).

Dentro dessa perspectiva, as dificuldades no exercício da prática pedagógica dos discentes nas disciplinas de estágio podem ser amenizadas nas instituições envolvidas através do desenvolvimento de um trabalho seguro, consistente, de formação ampla, flexível e planejado no intuito de diminuir o choque de realidade e ser um canal de segurança para o discente e professor iniciante (KRUG, 2011).

\section{ASPECTOS METODOLÓGICOS}

Neste estudo destacamos uma abordagem qualitativa, através da análise de conteúdo (BARDIN, 2011) de dados obtidos em uma investigação mais ampla em nível de mestrado. Assim, procuramos compreender as principais dificuldades relacionadas à atuação docente, em especial nas atividades de regência das disciplinas de Estágio I e Estagio II, 
cursadas no $9^{\circ}$ e $10^{\circ}$ períodos (semestres letivos), através da percepção de alunos e egressos do Curso de Ciências Biológicas/noturno da Universidade Federal de Uberlândia.

Com relação aos instrumentos de pesquisa utilizados neste recorte, adotamos questionários abertos, cujas perguntas buscavam esclarecer causas, superações e sugestões propostas, relacionadas às dificuldades encontradas no percurso dos estágios.

O questionário foi aplicado pessoalmente, quando adentramos na aula de estágio em um momento de atendimento com a professora da universidade, no final do $10^{\circ}$ período, do ano de 2016, direcionado para alunos da $7^{\mathrm{a}}$ Turma de Ciências Biológicas (estagiários). A participação dos respondentes foi de abrangência considerável, dos 21 estagiários que receberam o questionário, 16 responderam.

O questionário possuía três questões abertas: 1) Que causas você atribui a essas dificuldades? 2) Como você procurou superar essas dificuldades? 3) Que sugestões você proporia para superar essas dificuldades no âmbito do curso de formação inicial?

Foram também aplicados questionários abertos para os egressos que, em sua maioria, faziam parte da $1^{\mathrm{a}}$ turma do Curso Ciências Biológicas. Enviado por e-mail, no ano de 2016, possuía 8 questões abertas, das quais destacamos aquelas que se relacionam às dificuldades enfrentadas na docência e às contribuições do estágio supervisionado. A participação dos respondentes também foi bastante satisfatória; dos 24 egressos que receberam o questionário, 17 responderam.

\section{RESULTADOS E DISCUSSÕES}

Com as respostas obtidas no questionário aos estagiários, estabelecemos uma classificação de acordo com as características comuns, construindo as categorias de análise. No intuito de facilitar a identificação e preservar a identidade dos Estagiários, nomearemos os mesmos por siglas consecutivas. Exemplos: EST1, EST2, EST3... EST16.

A primeira questão proposta está relacionada às causas das dificuldades vivenciadas. Com as respostas obtidas construímos duas categorias: Estrutura escolar e Receptividade. A Estrutura escolar engloba a estrutura física da escola, grade horária, salas superlotadas, além de problemas ligados a fatores sociais, desmotivação dos alunos, indisciplina e valor social. Esses aspectos estiveram presentes em 14 respostas. A Receptividade abrange desde a forma como a escola recebe os estagiários até o acolhimento dos mesmos pelos alunos; contou com 3 respostas. 
A segunda questão está relacionada às medidas adotadas pelos estagiários para superar as dificuldades descritas, para a qual constituímos outras duas categorias: Materiais externos e Atividades dinâmicas (ou diversificação metodológica). Em Materiais externos os estagiários indicaram a utilização de recursos pessoais e principalmente recursos da universidade a partir do Laboratório de Ensino de Ciências e Biologia (como coleções secas, úmidas, de penas, crânios, de insetos, de lâminas, de livros didáticos e modelos de protozoários, esponjas, cnidários, ciclo de vida vegetais, jogos didáticos e os modelos Anatômicos em resina do corpo humano e também de célula vegetal, microscópios, lupas, equipamentos audiovisuais, computadores, acervo didático, material de papelaria, dentre outros materiais). Em Atividades dinâmicas (ou diversificação metodológica), os licenciandos relataram que, para superar as dificuldades com que se depararam no estágio, optaram por aulas mais criativas, em um modelo mais interativo, que exigia maior participação dos alunos, utilizando recursos que vão além dos tradicionais. Do total, 13 respostas se enquadraram nessa categoria.

A última questão se referia às sugestões propostas pelos estagiários para sanar as dificuldades enfrentadas durante o estágio. Constituímos cinco categorias, as quais denominamos: Observação, Práticas metodológicas, Suporte de material, Apoio institucional e Conjuntura da educação.

A primeira, Observação, está relacionada a uma queixa recorrente quanto ao tempo que os estagiários têm para se ambientar no contexto escolar, conhecer a rotina e familiarizar-se com a escola, o qual é insuficiente para se sentirem seguros, bem como para estabelecer vínculos com os alunos, considerados necessários para o desenvolvimento do estágio. 4 respostas se encaixaram nessa categoria. Para exemplificar essa categoria, citamos a resposta da licencianda EST1:

Acredito que, talvez, a entrada na escola mais cedo ajudaria muito, nós vamos para a escola e já começamos a dar aula, nós não temos tempo para conhecer bem a estrutura de uma sala de aula (EST 1).

A segunda diz respeito à Diversificação de práticas metodológicas, avançando para além das aulas tradicionais. 7 respostas se enquadram nesse grupo. É exemplificada pela estagiária EST2: 
que façam com que todos os alunos se envolvam em grupo para realizar e chegar a um objetivo (EST2).

A terceira enfatiza o Suporte de material, uma série de recursos pedagógicos que tendem a facilitar o processo de ensino e aprendizagem e proporcionam mais opções ao estagiário na hora de desenvolver aulas mais criativas e com metodologias diferenciadas. A estagiária EST3 expressou essa sugestão e afirmou que:

Como são questões relacionadas à estrutura das instituições, vejo que o apoio do LEN, com materiais, modelos e livros é de fundamental importância (EST3).

A quarta corresponde ao Apoio institucional em que um estagiário cita o PIBID Programa Institucional de Bolsa de Iniciação à Docência, o qual é destinado a inserir o licenciando no ambiente escolar, evidenciando que se fossem ofertados mais programas de formação como esse e que abrangesse mais alunos, provavelmente reduziria dificuldades. $\mathrm{O}$ estagiário EST4, na resposta a essa questão diz que, graças à sua experiência no PIBID, não enfrentou dificuldades durante o estágio.

A última diz respeito à Conjuntura da educação. Enfatiza que maiores investimentos no setor da educação atenuariam tais dificuldades, pois com mais recursos as escolas desempenhariam sua função com maior qualidade, garantiria melhores estruturas físicas e motivação profissional. Essa solução foi sugerida em 2 respostas.

Em síntese, as respostas dos estagiários podem ser resumidas no esquema da Figura 1.

Figura 1: Categorias para causas, enfrentamentos e sugestões para superação das dificuldades encontradas no estágio supervisionado 


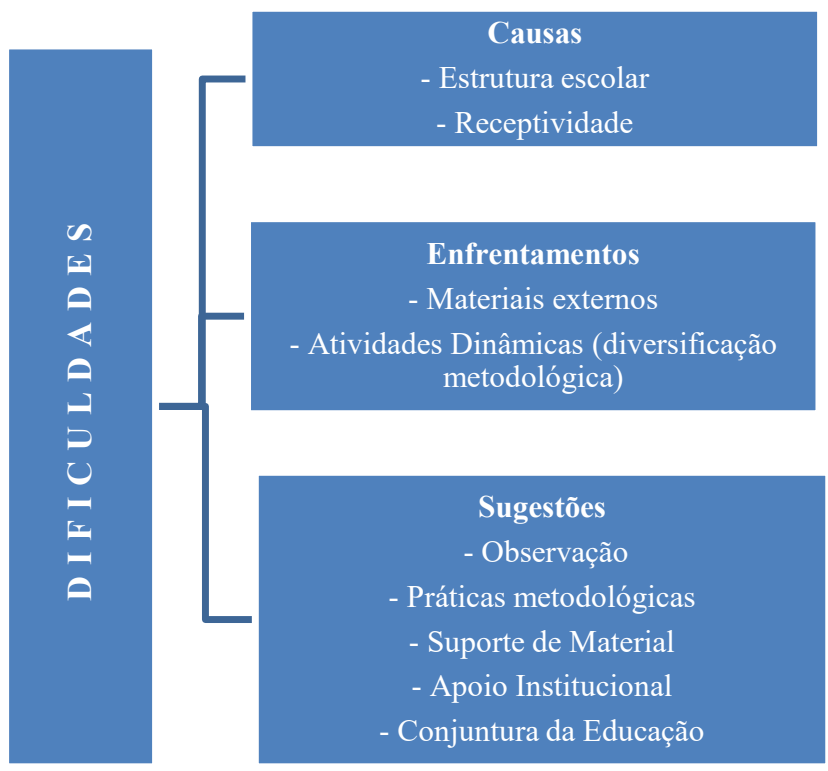

Nesse esquema estão agrupadas as categorias construídas, as quais estão associadas às causas, enfrentamentos e sugestões sobre as dificuldades. Apenas as categorias relacionadas à unidade de contexto Enfrentamentos dizem respeito ao estagiário, as demais se referem à escola ou ao desenvolvimento do estágio, este sob responsabilidade da universidade. Desta forma, os estagiários caracterizam uma atitude de transferência de responsabilidade, quer seja pelas causas que seja pela solução das dificuldades presentes no contexto de formação.

Dos 24 questionários enviados por e-mail aos egressos da turma 2013 do Curso de Ciências Biológicas, obtivemos 17 retornos. O objetivo principal desses questionários era compreender como as dificuldades enfrentadas no estágio foram superadas pelos egressos que estavam atuando na docência e como as disciplinas de prática de ensino e estágio supervisionado contribuíram para diminuir os impactos iniciais no ambiente escolar. No intuito de preservar a identidade dos egressos, nomeamos os mesmos por siglas consecutivas: EG1, EG2... EG17.

A partir da análise das respostas verificamos que, dos 17 respondentes, 7 afirmaram exercer a profissão. Quando perguntamos aos que não exercem a função o que determinou esse afastamento, as justificativas foram as seguintes: Pós-graduação - 4 respostas, Desinteresse pela profissão - 5 respostas; e falta de oportunidade -1 resposta.

O desinteresse pela profissão reúne respostas que justificam o porquê de alguns licenciados não se motivarem a trabalhar na área. Encontramos como principais fatores: a 
desvalorização da profissão, insegurança e despreparo para atuar, falta de afinidade e, ainda, que o curso não despertou interesse pela docência.

Uma questão específica indagou sobre as influências que as disciplinas de práticas de ensino e estágio exerceram para a relação do licenciado com a docência, seja para aproximar ou afastá-lo da profissão. A partir da análise dos dados obtidos reunimos as respostas em cinco categorias: Nenhuma influência, Influência positiva do estágio, Influência negativa do estágio, Influência positiva das práticas de ensino e Influência negativa das práticas de ensino.

$\mathrm{Na}$ Influência positiva do estágio, 11 respostas indicaram que o estágio colaborou para a aproximação com a docência. A licenciada EG1, por exemplo, afirma que:

[...] foi no estágio que vivenciei a realidade de estar na sala de aula e ter de enfrentar os desafios, a responsabilidade e a sobrecarga de trabalho (EG1).

Em Nenhuma influência, 4 respostas foram agrupadas com conteúdos semelhantes, destacamos como exemplo a resposta da licenciada EG2:

Tais disciplinas não tiveram influência alguma na minha decisão de exercer ou não a profissão docente, talvez por esse fato senti que elas deixaram a desejar nessa importante decisão (EG2).

Na Influência negativa do estágio, 3 respostas indicaram que a experiência de estágio foi responsável por desestimular o então licenciando em seguir a carreira docente, como o caso da resposta da licenciada EG3, que mencionou ter sido durante o estágio que percebeu não ter vocação para a profissão de professor.

$\mathrm{Na}$ Influência positiva das práticas de ensino, em 8 respostas observamos que as disciplinas de prática de ensino foram importantes para a formação do professor, colaborando assim para sua aproximação com a docência, por exemplo a licenciada EG3:

Essas disciplinas de suma importância para a minha decisão por escolher a docência. Os professores (a maioria deles) souberam despertar a vontade pela docência, criando uma imagem de que é possível mudar a realidade pela educação, apesar dos imensos obstáculos que o sistema educacional brasileiro constrói ao tentar impor metodologias/ didáticas/ políticas/ pedagógicas arcaicas (EG3).

E na Influência negativa das práticas de ensino, 3 respostas condizem com essa categoria. Dentre elas, podemos citar: 
Sim, principalmente meu afastamento. As disciplinas de práticas de ensino não são tão práticas como o nome diz, foram poucas as vezes que foram oportunizadas práticas voltadas para a formação de professores e vivência de como ensinar... (EG4)

Uma questão específica tratou das principais dificuldades enfrentadas no contexto de atuação profissional. Nessa questão optamos por analisar apenas as respostas dos egressos que atuam no contexto escolar, ou seja, dos 7 (dentre os 17) que exercem a profissão.

Assim, em um primeiro momento, agrupamos as dificuldades detalhadas em macro categorias devido à grande diversidade de respostas obtidas, visto que havia dificuldades apresentadas pelos egressos que pertenciam ao mesmo conjunto, remetendo significados semelhantes. Dessa análise formulamos quatro categorias, que são: Dificuldades associadas ao Sistema educacional/escola - 15 respostas, Dificuldades associadas ao aluno 12 respostas, Dificuldades associadas ao professor -6 respostas, Dificuldades associadas ao currículo -4 respostas.

A categoria Dificuldades associadas ao Sistema educacional/escolar engloba as dificuldades enfrentadas no exercício institucionalizado da profissão, na qual foram mencionadas as principais dificuldades: Falta de infraestrutura, Má remuneração, Burocracia. Dentre essas dificuldades citamos o exemplo descrito pela licenciando EG10:

\footnotetext{
$\mathrm{Na}$ escola privada onde atuo, o mais difícil é a parte burocrática, que limita a prática docente. O fato de ter que seguir apostila, ter que tabular notas e dados para apresentar para a coordenação, papéis para preencher, enfim, a criatividade e a liberdade de desenvolver novas metodologias não existe, pois não sobra tempo (EG10).
}

$\mathrm{Na}$ categoria Dificuldades associadas ao aluno agrupamos respostas onde os respondentes citaram dificuldades como: Indisciplina, Falta de apoio da família, Falta de domínio por parte dos alunos e Desinteresse dos estudantes. Assim, exemplificamos com o que foi descrito pela licenciada EG9.

Desinteresse por parte de pais e alunos que acarretam a falta de comprometimento, a indisciplina, entre outros (EG9).

$\mathrm{Na}$ categoria Dificuldades associadas ao professor foram citadas dificuldades como: Curto tempo para planejar, Falta de união entre todos os profissionais que trabalham na escola, Despreparo profissional, Preparo de aulas diferentes (com práticas). Assim, a licenciada EG11 destaca que: 
Pouco tempo para preparar melhor minhas aulas, de acordo com o perfil de cada turma. Em consequência da baixa remuneração eu preciso trabalhar em dois turnos e faço mestrado, para melhorar a renda salarial, sobrando-me pouco tempo para preparar aulas elaboradas e levando em consideração o perfil de cada turma (EG11).

E a categoria Dificuldades associadas ao currículo é composta pelas respostas que relatam serem as principais dificuldades enfrentadas no contexto profissional docente: Falta de autonomia e Excesso de conteúdo para a carga horária estabelecida. A licenciada EG3 destaca em sua resposta:

\begin{abstract}
As escolas onde já lecionei são "engessadas" e dão pouca liberdade ao profissional em como avaliar os alunos, exigindo provas sempre do mesmo modelo. Os recursos disponíveis também afetam negativamente a atuação dos professores, ainda mais em se tratando de conteúdos que necessitam de imagens, modelos, esquemas, animações, como são os conteúdos de Ciências Naturais, que devem ser ilustrativos e possuem carga excessiva de informações para uma grade horária limitada nas escolas (EG3).
\end{abstract}

Em síntese, as principais dificuldades de atuação estão agrupadas na Tabela 2.

Tabela 1: Principais DIFICULDADES DE ATUAÇÃO

\begin{tabular}{|c|c|c|c|}
\hline \multicolumn{2}{|r|}{ Categorias } & \multicolumn{2}{|c|}{ Frequência } \\
\hline \multirow{3}{*}{ Sistema educacional/escola } & Falta de infraestrutura & 11 & \multirow{3}{*}{15} \\
\hline & Má remuneração & 3 & \\
\hline & Burocracia & 1 & \\
\hline \multirow{4}{*}{ Aluno } & Indisciplina & 4 & \multirow{4}{*}{12} \\
\hline & Falta de apoio da família & 4 & \\
\hline & Falta de domínio, por parte dos alunos & 2 & \\
\hline & Desinteresse dos estudantes & 2 & \\
\hline \multirow{4}{*}{ Professor } & Curto tempo para planejar & 2 & \multirow{4}{*}{6} \\
\hline & Preparar aulas diferentes, com prática & 2 & \\
\hline & Despreparo profissional & 1 & \\
\hline & Falta de união entre todos os profissionais que trabalham na escola & 1 & \\
\hline \multirow{2}{*}{ Currículo } & Falta de autonomia & 3 & \multirow{2}{*}{4} \\
\hline & Excesso de conteúdo para a carga horária & 1 & \\
\hline
\end{tabular}

$\mathrm{Na}$ questão sobre as causas atribuídas às dificuldades citadas obtivemos uma grande variedade de respostas, assim separamos em micro e macro categorias. Criamos seis macrocategorias: Sistema educacional -14 respostas, Professor -5 respondentes, Família -5 respostas, Currículo - 2 respostas, Graduação - 3 respostas, Aluno - 3 respostas.

A categoria Sistema educacional obteve maior número de respostas, na qual os egressos relatam que as causas atribuídas às dificuldades na atuação profissional são: Falta de investimento, Falta de apoio da supervisão, Burocracias, Gestão escolar, Políticas públicas. Exemplificando essa categoria o licenciado EG12 relata: 
[...] são as diversas burocracias que muitas vezes nos impedem e nos desmotivam a ir além do mesmo modelo de educação que estamos inseridos. Desde o salário, que é ridículo para sobreviver, à distribuição de horários para atuar na sala de aula, que não dá tempo para quase nada, o modo como os estudantes ficam trancafiados por horas em sala de aula e como o professor é cobrado para despejar muitas informações em 50 minutos, cumprir diários, falta de estrutura na escola e etc. (EG12).

A categoria Professor é composta por causas como: Falta de experiência, Falta de formação continuada, Dificuldade com os conteúdos. O licenciado EG14 comenta que:

A falta de vivência durante a faculdade, porque acredito que teríamos que ter essa desde o primeiro período, pois ganharíamos bagagem para enfrentarmos o mercado de trabalho (EG14).

A categoria Família corresponde a uma causa principal atribuída às dificuldades na atuação profissional, é a transferência da responsabilidade familiar para a escola. Para exemplificar esse grupo a licenciada EG11 afirma que:

A desestruturação e falta de valores dos alunos eu atribuo à família (nossa sociedade) que não sabe ou não quer saber, que a Constituição brasileira define que a educação básica de nossas crianças e jovens é dever de todos. Ou seja, a responsabilidade de educar não é só da escola (pública e/ou particular) e sim da escola, dos pais e da sociedade (EG11).

As categorias Currículo e Graduação abrangem respostas que correspondem respectivamente à ineficiência do currículo e à formação profissional precária. Dentre as respostas que se enquadram nessa categoria, destaca-se a da licenciada EG6:

Poucas pessoas estão realmente preparadas para enfrentar os desafios de suas profissões. Essa falta de preparo pode advir de uma má formação profisssional e também de questões pessoais (EG6).

A categoria Aluno é composta por uma das principais dificuldades encontradas pelos professores que responderam a este questionário e que se destaca nos dias atuais como uma das principais queixas dentro do âmbito escolar, a indisciplina, sendo aqui descrita como uma das causas atribuída às dificuldades na atuação profissional. Exemplificada pela licenciada EG13:

[...]os alunos rebeldes são, na maioria, o resultado de pais pouco presentes. Seja por trabalho em excesso ou falta de paciência com o filho. Em contrapartida a falta de 
experiência em conduzir e ministrar as aulas também pode ser um fator limitante da indisciplina (EG13).

Em síntese, as principais causas das dificuldades estão apresentadas na Tabela 2.

Tabela 2: CAUSAS das dificuldades

\begin{tabular}{|c|c|c|c|}
\hline \multicolumn{2}{|r|}{ Categorias } & \multicolumn{2}{|c|}{ Frequência } \\
\hline \multirow{5}{*}{ Sistema educacional/escola } & Falta de investimento & 8 & \multirow{5}{*}{14} \\
\hline & Políticas públicas & 3 & \\
\hline & Falta de apoio da supervisão & 1 & \\
\hline & Burocracias & 1 & \\
\hline & Gestão escolar & 1 & \\
\hline \multirow{3}{*}{ Professor } & Falta de experiência & 3 & \multirow{3}{*}{5} \\
\hline & Dificuldade com os conteúdos & 1 & \\
\hline & Falta de formação continuada & 1 & \\
\hline Família & Família que transfere sua responsabilidade para a escola & 5 & 5 \\
\hline Aluno & Indisciplina & 3 & 3 \\
\hline Graduação & Má formação profissional & 3 & 3 \\
\hline Currículo & Ineficiência do currículo & 2 & 2 \\
\hline
\end{tabular}

Quando perguntamos quais eram as sugestões que os egressos dariam para superar as dificuldades encontradas, obtivemos dentro de uma mesma resposta uma série de sugestões e organizamos as mesmas em conjuntos e, posteriormente, reagrupamos em quatro categorias, englobando toda a diversidade de respostas obtidas, sendo elas associadas ao Sistema educacional - 17 respostas, ao Professor - 13 respostas, ao Currículo - 4 respostas e à Família -2 respostas.

A categoria associada ao Sistema educacional compreende respostas nas quais os egressos consideram que para superar tais dificuldades é preciso: Aumentar os investimentos/melhorar infraestrutura/valorizar o professor, ter punições mais severas para alunos indisciplinados, mudanças nas políticas educacionais, aumento do número de profissionais especializados para alunos com necessidades especiais, escola integral, redução da quantidade de alunos por sala, aumentar a autonomia do professor e aumentar a interdisciplinaridade. A licenciada EG5 afirma:

Reduzir a quantidade de alunos nas salas de aula, o professor deveria de ter mais autonomia e não só se ver submisso aos alunos em que esses podem fazer tudo e o professor dependendo não pode nem lhe chamar a atenção. Se os alunos fossem realmente obrigados a respeitar os seus professores, a situação do ensino brasileiro seria diferente (EG5). 
A categoria Professor reúne sugestões como: formação continuada, mobilização da classe docente, vínculo com uma única escola e criatividade para driblar as dificuldades. Segundo as licenciadas EG3 e EG11:

[...] tentar mobilizar seus pares a exigir mais dos governantes para a melhoria da educação, como a reforma política e do sistema educacional do Brasil, sugerindo estudiosos e pesquisadores que possam contribuir para a melhoria da educação (EG3).

[..] quem deseja ser professor precisa, além do diploma de licenciado, um diploma de mestre em educação; pagar um salário digno para que os professores não tivessem que fazer jornadas duplas ou triplas de trabalho, e exigir dos professores dedicação exclusiva, como já acontece nas Universidades e Institutos Federais do país... (EG11).

$\mathrm{Na}$ categoria Currículo estão inclusas respostas dos egressos que sugerem alterações vinculadas a problemas com o currículo, nessa ramificação incluem: reformulação curricular da licenciatura e aumento da interdisciplinaridade. Destacamos como exemplo a resposta da licenciada EG6:

O Ensino de uma forma geral deve passar por um processo de mudanças, desde os anos iniciais até a pós-graduação. É muito difícil citar pontos específicos que devem ser mudados, visto que, tudo está interligado e consequentemente forma efeito "cascata" nos mais diversos aspectos da Educação (E6).

A categoria Família abarca respostas pertencentes ao grupo de sugestões referentes à parceria escola/família e à necessidade dos pais de alunos serem mais presentes na vida escolar de seus filhos. A licenciada EG9 exemplifica:

Mais responsabilidade para as famílias, que estas encontrassem mais espaço em suas vidas (filhos) e no ambiente escolar (EG9).

A Tabela 3 apresenta as sugestões apontadas para superar as dificuldades de atuação.

Tabela 3: SUGESTÕES para superar as dificuldades

\begin{tabular}{l|l|c|}
\hline \multicolumn{1}{c|}{ Categorias } & Frequência \\
\hline \multirow{4}{*}{$\begin{array}{l}\text { Sistema } \\
\text { educacional }\end{array}$} & Aumentar os investimentos/melhorar infra/valorizar o professor & 8 \\
\cline { 2 - 3 } & Punições mais severas para alunos indisciplinados & 3 \\
\cline { 2 - 3 } & Mudanças nas políticas educacionais & 2 \\
\cline { 2 - 3 } & $\begin{array}{l}\text { Aumento do número de profissionais especializados para alunos com } \\
\text { necessidades especiais }\end{array}$ & 1 \\
\cline { 2 - 4 } & Escola integral & 17 \\
\cline { 2 - 3 } & Redução da quantidade de alunos por sala & 1 \\
\cline { 2 - 3 } & Aumentar a autonomia do professor & 1 \\
\hline
\end{tabular}




\begin{tabular}{l|l|c|c}
\hline \multirow{4}{*}{ Professor } & Formação continuada & 6 & \multirow{2}{*}{$\mathbf{1 3}$} \\
\cline { 2 - 3 } & Mobilização da classe & 4 & \\
\cline { 2 - 3 } & Vínculo com uma única escola & 2 & \multirow{2}{*}{$\mathbf{4}$} \\
\cline { 2 - 3 } & Criatividade para driblar as dificuldades & 3 & \multirow{2}{*}{$\mathbf{2}$} \\
\hline \multirow{2}{*}{ Currículo } & Reformulação curricular da licenciatura & 1 & \\
\cline { 2 - 4 } & Aumentar a interdisciplinaridade & 2 & $\mathbf{2}$ \\
\hline \multirow{2}{*}{ Família } & Parceria escola/família &
\end{tabular}

\section{CONSIDERAÇÕES FINAIS}

Ao refletirmos sobre as principais dificuldades identificadas nos dados coletados, constatamos uma maior convergência com questões relacionadas ao sistema educacional/escolar e ao aluno, seja pela heterogeneidade característica de turmas de estágio, falta de interesse, indisciplina ou falta de conhecimentos prévios, ou seja, situações normalmente presentes no contexto da sala de aula, mas que pela inexperiência do estagiário, o que é plausível por estar em momento de aprendizado da profissão, tornam-se mais latentes. Esse desconforto do licenciando poderia ser atenuado caso houvesse maior oportunidade de contato com o contexto escolar ao longo da graduação.

Nas questões abertas dispostas no questionário dos estagiários, quanto às causas das dificuldades, foram citadas desde elementos voltados à infraestrutura da escola, recursos didáticos, salas superlotadas, carga horária insuficiente, além de problemas associados a um panorama mais amplo de ordem social.

Percebemos, ao analisar esses questionários, que esses problemas que afetam diretamente o trabalho do professor em sala de aula têm raízes mais profundas e escapam à possibilidade dele de solucioná-los isoladamente. Porém, ao analisarmos as alternativas utilizadas pelos estagiários para driblar essas dificuldades, comparecem estratégias bastante promissoras, como variar recursos pedagógicos e metodologias, a fim de despertar o interesse do aluno e promover o aprendizado.

Através das respostas obtidas junto aos egressos, identificamos as principais razões para seu afastamento do exercício da profissão, as quais residem principalmente no desinteresse pela mesma. Segundo os relatos dos respondentes também pudemos perceber que a experiência negativa vivenciada no estágio foi um dos desmotivadores para o exercício da docência, e associados a ela estão as condições de trabalho, baixos salários, entre outros.

Com relação aos egressos que exercem o magistério, quando perguntamos sobre as dificuldades que enfrentam na atuação profissional, identificamos novamente que as 
dificuldades associadas aos alunos e ao sistema como um todo são muito destacadas, evidenciam a necessidade e a importância da formação continuada.

Nossas análises apontam para um conjunto de necessidades formativas que está relacionado às dificuldades efetivamente encontradas pelos licenciandos. Desconsiderá-las poderia levar a uma postura dogmática, em que os conteúdos formativos são meramente conceituais, deixando de lado atuações criativas e reflexivas quanto à realidade que vão enfrentar.

Por outro lado, é necessário ponderar quanto à perspectiva da reprodução presente na formação inicial de professores, pautada pela observação e tentativa de reprodução de uma prática considerada “modelar” (PIMENTA e LIMA, 2011).

Ressaltamos a importância de se instrumentalizar os licenciandos para as observações no âmbito escolar. Entretanto, não basta que os licenciandos entrem em contato com o ambiente do qual fizeram parte por, pelo menos, doze anos de sua formação, sem a necessária fundamentação teórica e teorias de aprendizagens para constituir um olhar efetivamente perscrutador, crítico e investigativo. Assim, Ghedin e Franco, descrevem que:

(...) o olhar há de ser crítico, e a crítica surge com a dúvida, que questiona o modo pelo qual as coisas se apresentam. Por isso, deve-se educar o olhar, pois, sem o olhar crítico, há o risco de reproduzir apenas as representações do mundo, suas ilusões, e não o mundo em sua concretude, transformado pela arte de fazê-lo humano. Para instaurar um processo de transformação, convém educar o olhar noutras direções (GHEDIN e FRANCO, 2011, p. 80).

Outro aspecto a ser ressaltado é o necessário deslocamento da atenção dos estagiários de seus próprios atributos (tempo de observação, choque com a realidade, insegurança e falta de conhecimento) para alguns atributos dos alunos das turmas de regência (indisciplina e falta de conhecimento desses). Sem esta mudança de foco, mantém-se uma ênfase no próprio desempenho em sala de aula, conformando dificuldades comuns em outras pesquisas da área. Essas dificuldades precisam ser compreendidas e enfrentadas, pois geram intensos conflitos e ansiedades na busca do controle e de modos de se relacionar com a classe.

Nessa perspectiva, as instâncias de formação poderiam promover e incentivar seus alunos a irem ao encontro da sala de aula, a vivenciarem o ambiente escolar, pois, como indicado, as observações no âmbito escolar são de extrema importância. Esse olhar implica em percepção e interpretação do "objeto" (nesses casos de natureza social), para que o mesmo possa ser compreendido. Afinal, o olhar de que tratamos presume uma aproximação com a pesquisa e: 
(...) a pesquisa em educação possui uma particularidade incomparável com as outras ciências, especialmente porque os objetos das ciências da educação e seus métodos implicam processos diferenciados de acesso ao real (GHEDIN e FRANCO, 2008, p. 72).

O que importa nos fatos humanos não é a causa, mas sua significação, objetivos e valor. Nesse contexto, o sentido que se quer compreender só existe quando algo é significativo a ponto de se lhe atribuir sentido e significado.

O licenciando, ao passar pela experiência de estágio supervisionado, vivencia o primeiro passo para a iniciação de sua trajetória através das atribuições próprias da função do professor, num momento decisivo para seu desenvolvimento profissional futuro.

Portanto, para que se criem vínculos com o âmbito escolar e sejam enfrentados conflitos futuros e dificuldades nas regências iniciais, torna-se necessário que as instituições formadoras de futuros professores promovam atividades que integrem seus alunos desde os anos iniciais de graduação até os estágios obrigatórios, aliem teoria e prática, busquem estímulos para a construção de saberes aplicados às exigências curriculares, e motivem seus acadêmicos a seguirem na profissão docente.

\section{REFERÊNCIAS}

ALMEIDA, S.T.S. A importância do estágio supervisionado na formação profissional do assistente social. In: III Simpósio mineiro de assistentes sociais, CRESS, Belo Horizonte, p. 6, 2013.

AZEVEDO, A. A.; WILTEMBURG, V. A. Professores iniciantes e o 'choque de realidade' - o que nos revelam algumas pesquisas. In: XI Congresso Nacional de Educação EDUCERE, Curitiba, 2013.

CICILLINI, G. A. Conhecimento científico e conhecimento escolar: aproximações e distanciamentos. In: CICILLINI, G. A.; NOGUEIRA, S. V. (Org.) Educação escolar: políticas, saberes e práticas pedagógicas. Uberlândia: EDUFU, p. 37-66, 2002.

CICILLINI, G. A. Professores universitários e sua formação: concepções de docência e prática pedagógica. In: NOVAIS, G. S.; CICILLINI, G. A. (Org.). Formação docente e práticas pedagógicas: olhares que se entrelaçam. Araraquara: Junqueira \& Martins; Belo Horizonte: FAPEMIG; p. 19-43, 2010.

GHEDIN, E.; FRANCO, M. A. S. Questões de método na construção da pesquisa em educação. São Paulo: Cortez, 2011.

KRUG, H.N. Os problemas/dificuldades na prática pedagógica nos estágios curriculares I-IIIII na percepção dos acadêmicos da Licenciatura em Educação Física do CEFD/UFSM. In: Revista Digital, N. 158, Santa Maria, 2011. 
MACIEL, M. E. O estágio supervisionado na formação docente: espaço de desafios, possibilidades e aprendizagens de futuros professores. In: XVI ENDIPE - Encontro Nacional de Didática e Práticas de Ensino, Campinas, 2012.

PEQUIÁ, R. S. S.; ROSA, G. R. Pelos caminhos do estágio supervisionado em Serviço Social: uma análise à luz das novas diretrizes curriculares. In: Revista Serviço Social \& Realidade, Franca, v. 19, n. 1, p. 153-172, 2010.

PIMENTA, S.; LIMA, M. Estágio e Docência. 6. Ed - São Paulo: Cortez, 2011.

ROCHA, T. M. J. R. A transição de aluno a professor: Dificuldades e desafios. Instituto Politécnico de Lisboa Escola Superior de Educação de Lisboa, Dissertação de Mestrado, Lisboa, 2013.

TARDIF, M. Saberes docentes e formação profissional. Petrópolis: Vozes, 2007.

TARDIF, M.; RAYMOND, D. Saberes, tempo e aprendizagem do trabalho no magistério. In: Educação \& Sociedade, Campinas, v. 21, n. 73, dez. 2000.

VALSECCHI S. A. E.; NOGUEIRA S. M. Comunicação professor-aluno: aspectos relacionados ao estágio supervisionado. In: Revista Ciência, Cuidado e Saúde, Maringá, v. 1, n. 1, p. 137-143, 2002. 